\title{
Rate of inbreeding and effective population size in four major South African dairy cattle breeds
}

\author{
A. Maiwashe", K.A. Nephawe, R.R. van der Westhuizen, B.E. Mostert and H.E. Theron \\ ARC-Livestock Business Division, Private Bag X2, Irene 0062, South Africa
}

\begin{abstract}
Pedigree information on the registered South African Ayrshire $(n=47$ 116), Guernsey $(n=18766)$, Holstein ( $n=892458)$ and Jersey $(n=314403)$ breeds was analyzed to determine the rate of inbreeding and effective population sizes for the period 1960 to 2003. Inbreeding coefficients were calculated using the Animal Breeder's Tool Kit. The mean inbreeding coefficients for 2003 were $2.02 \%, 2.04 \%$, 2.30\%, and $3.05 \%$ for the Ayrshire, Guernsey, Holstein and Jersey, respectively. The corresponding rates of inbreeding per year were $0.05 \%, 0.05 \%, 0.06 \%$, and $0.07 \%$ indicating that inbreeding is accumulating at a slightly higher rate in Jersey compared to the other three breeds. However, the rates of inbreeding in the current study are still considerably lower than the acceptable rate of less than $0.5 \%$ per year. Estimates of effective population sizes were 148, 165, 137, and 108 for the Ayrshire, Guernsey, Holstein and Jersey, respectively. Results indicate that the impact of inbreeding on genetic variability is still minimal. However, the impact of inbreeding on phenotypic performance on traits of economic importance was not investigated in the current study and should therefore receive future consideration.
\end{abstract}

Keywords: Dairy cattle, genetic diversity, pedigree analysis

${ }^{\#}$ Corresponding author. E-mail: norman@arc.agric.za

\section{Introduction}

Inbreeding refers to the mating together of individuals that are more closely related than would be the case if mating was at random (Falconer \& Mackay, 1996). The consequence of the inbreeding process is the reduction (1) in the genetic variability within a population and (2) in performance mainly in traits that are associated with the fitness of an individual (e.g. fertility). While the impact of inbreeding in populations of large sizes is negligible, its effect in typical livestock population where selective breeding is practised, cannot be ignored.

Several studies in different countries indicate that inbreeding is increasing in dairy cattle populations. Young \& Seykora (1996) obtained rates of inbreeding of 0.11\% per year for the United States Holsteins for the period 1960 to 1990 . A higher rate of inbreeding ( $0.20 \%$ per year) for the same population was reported by Wiggans et al. (1995). The rate of inbreeding for the period 1992 to 2002 of $0.17 \%$ per year was reported in United Kingdom Holsteins (Kearney et al., 2004). Furthermore, effective population sizes have also been estimated to be low for the major dairy cattle breeds in the United States (Weigel, 2001). These increases in rates of inbreeding have been attributed mainly to the use of reproductive technologies (e.g. artificial insemination (AI), multiple ovulation and embryo transfer) and availability of national and across-country estimated breeding values (EBV) provided by the International Bull Evaluation (INTERBULL) (Weigel, 2001, Kearney et al., 2004). The EBVs are currently estimated using an animal model that incorporates all available sources of information (e.g. own, progeny and parents' performance) such that EBVs of superior individuals tend to be highly correlated, thereby increasing the probability of co-selection of relatives.

In South Africa, semen from foreign sires is currently widely used in the dairy industry, e.g. the proportion of progeny sired by foreign sires between 2000 and 2003 ranges from 25 to 36\% for the four major dairy breeds in the country i.e. the Ayrshire, Guernsey, Holstein and Jersey. The semen is imported mainly from Australia, Austria, Canada, Germany, Denmark, Finland, France, Isle of Jersey, Italy, Netherlands, New Zealand, Switzerland and the United States. Semen from Taurus, the local AI company, is also used extensively in the South African dairy industry. Literature estimates of rate of inbreeding and effective population size are not currently available for the South African dairy cattle breeds even though the breeding practices are similar to countries such as the United States and Canada where rapid increases in levels of inbreeding have been reported. The objective of the current study was to determine the rates of 
inbreeding and effective population sizes for the four major South African dairy cattle breeds participating in the National Dairy Cattle Performance Testing Scheme.

\section{Material and Methods}

The breeds considered in the current study were the South African Ayrshire, Guernsey, Holstein and Jersey. Pedigree data including animal, sire and dam identification and date of birth were obtained from the Integrated Registration and Genetic Information System database. The data also included graded and imported animals. Pedigree information of imported ancestors was retrieved from the INTERBULL database. These pedigrees were traced as far back as possible. Considering animals born after 1960, the number of generations of complete pedigree information ranged from 2 to 7 across breeds with the mean of 3.1, 2.8, 3.1 and 3.4 generations for the Ayrshire, Guernsey, Holstein and Jersey, respectively.

Editing of the data included checking the integrity of the pedigree (e.g. animals that appeared as both a sire and a dam, animals that are progeny of themselves, and progeny that were born before their parents) using the "stack_ped” tool of the Animal Breeder's Tool Kit (ABTK), developed by Golden et al. (1992). The "stack_ped" tool also ensures that the records are ordered chronologically by age. The total number of usable records for the period 1960 to 2003 was 46 968, 18 646, 890958 and 313960 for the Ayrshire, Guernsey, Holstein and Jersey, respectively.

Inbreeding coefficients for each animal were computed using the "ainv" tool of the ABTK. This tool implements the algorithm of Meuwissen \& Luo (1992) which was developed for calculating inbreeding in large populations. For the purpose of comparison with similar studies 1960 was chosen as the base year by setting the parents of animals born before 1960 to be unknown such that the average inbreeding of animals born in 1960 was zero by definition.

The effective population size ( $\mathrm{Ne}$ ) was calculated as follows (Falconer \& Mackay, 1996):

$$
\mathrm{Ne}=\frac{1}{2 \Delta \mathrm{F}_{\mathrm{L}}}
$$

and

$$
\Delta \mathrm{F}_{\mathrm{L}}=\left(\frac{\sum \Delta \mathrm{F}_{\mathrm{t}-1, \mathrm{t}}}{\mathrm{k}-1}\right) \mathrm{L}
$$

and

$$
\Delta \mathrm{F}_{\mathrm{t}-1, \mathrm{t}}=\frac{\mathrm{F}_{\mathrm{t}}-\mathrm{F}_{\mathrm{t}-1}}{1-\mathrm{F}_{\mathrm{t}-1}}
$$

where $\Delta \mathrm{F}_{\mathrm{L}}$ is the rate of inbreeding per generation, $\Delta \mathrm{F}_{\mathrm{t}-1, \mathrm{t}}$ is the rate of inbreeding between years $\mathrm{t}-1$ and $\mathrm{t}, \mathrm{F}_{\mathrm{t}-1}$ and $\mathrm{F}_{\mathrm{t}}$ are the average inbreeding levels at years $\mathrm{t}-1$ and $\mathrm{t}$, respectively, $\mathrm{L}$ and $\mathrm{k}$ are the generation interval and number of years considered (e.g. 1960 to 2003), respectively. The generation interval (L) was defined as the average age of the parents when their offspring that are destined to be parents are born. Four selection pathways (e.g. sires of sires, dams of sires, sires of dams and dams of dams) are typical of dairy breeding programs and therefore $\mathrm{L}$ was computed as an average of generation intervals for the four pathways. Further analysis included calculating the annual mean number of progeny per sire.

\section{Results and Discussion}

The percentage of animals with both parents known for the period considered in the current study is given in Figure 1. For the most part of the period 1960 to 1975 at least $70 \%$ of the population was foundation animals in the four breeds. A rapid increase in the proportion of animals with both parents known occurred during the period 1975 to 1985 . In 2003 the proportion of animals with both parents known ranged from 70\% for the Guernsey to $90 \%$ for the Jersey with the Ayrshire and Guernsey being intermediate. The difference in the proportion of animals with both parents known was not dramatic among the four breeds and therefore the impact of incompleteness of pedigree on estimates of inbreeding should be comparable among the breeds. 


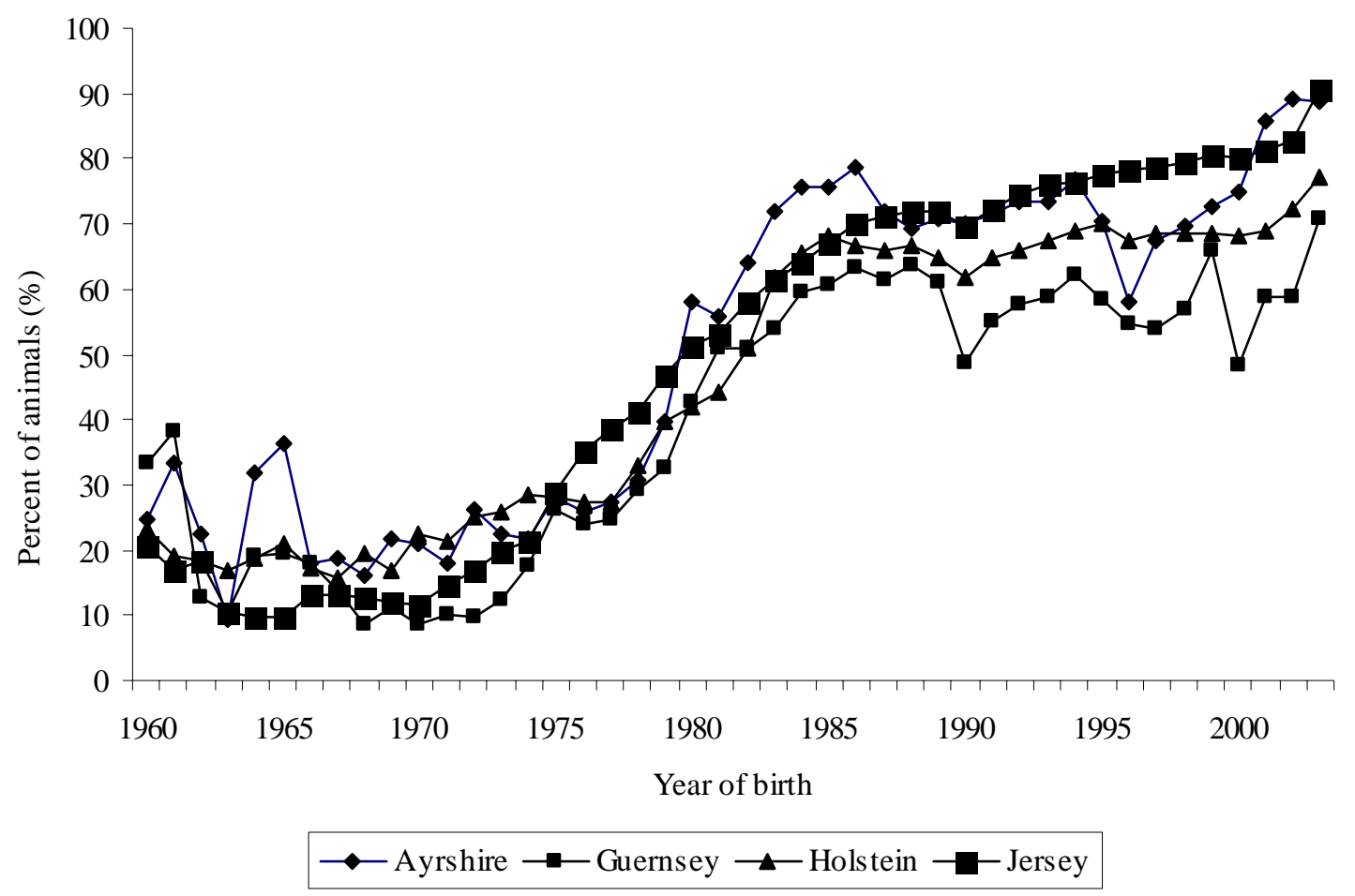

Figure 1 Percentage of animals with both parents known by year of birth

The annual registrations for the four breeds are given in Figure 2. The trends in the annual registrations for the Holstein and Jersey were similar and could be divided into three intervals: the periods of (1) mild increase (1960 to 1970), (2) rapid increase (1970 to 1987 for the Holstein and 1970 to 1996 for the Jersey), (3) no increase followed by a decline (1988 to 2003 for the Holstein and 1997 to 2003 for the Jersey). It is clear from Figure 1 that the Holstein was the dominant breed in the South African dairy industry for most of the period studied. However, the current trend demonstrates a decline in the Holstein's popularity with the gap for the annual registrations narrowing between the Holstein and the Jersey. In fact, the Holstein population has decreased by almost half within the last seven years while the Jersey has only declined by about 20\% between 2002 and 2003. The current decline in dairy populations has also been reported in other countries (Thompson et al., 2000a; b).

Through the entire period the Ayrshire and the Guernsey have had minority status. While the trend is positive for the Ayrshire, the annual registrations in the Guernsey seem to be constant over time. However, the proportion of these two breeds industry-wide has increased in the last few years due to the decline in the Holstein and the Jersey populations.

Results on generation intervals are presented in Table 1 . Generation interval refers to the average age of the parents when their progeny that in turn become parents are born. The four selection paths (i.e. the sire of sires, sire of dams, dams of sires, and dams of dams) typical of the dairy industry were taken into account when calculating the generation interval. The Ayrshire has the longest average generation interval while the Guernsey exhibited the shortest generation interval with the other two breeds being intermediate. However, the average generation intervals were comparable among the breeds. These results could be due to the use of AI whereby semen from certain sires is used extensively over time and therefore resulting in sires being used beyond their lifespan. The breeding policy also determines how long natural sires are used within herds.

Figure 3 shows a curvilinear relationship between the average level of inbreeding and time. This relationship is typical in livestock species. While the inbreeding trends tended to be smooth for the Holstein and Jersey, there was some local randomness in the direction of inbreeding for the Ayrshire and Guernsey. These patterns could be explained by the small population sizes for the Ayrshire and the Guernsey. The first 30 years (i.e. 1960 to 1990) were characterized by a mild increase in the level of inbreeding while the period 1990 to 2003 showed a rapid increase for all the breeds. The average levels of inbreeding in 2003 were 
2.02\%, 2.04\%, 2.30\%, and 3.05\% for the Ayrshire, Guernsey, Holstein and Jersey and the corresponding maximum inbreeding coefficients were $28.6 \%, 30.4 \%$, $37.5 \%$ and $34.6 \%$, respectively.

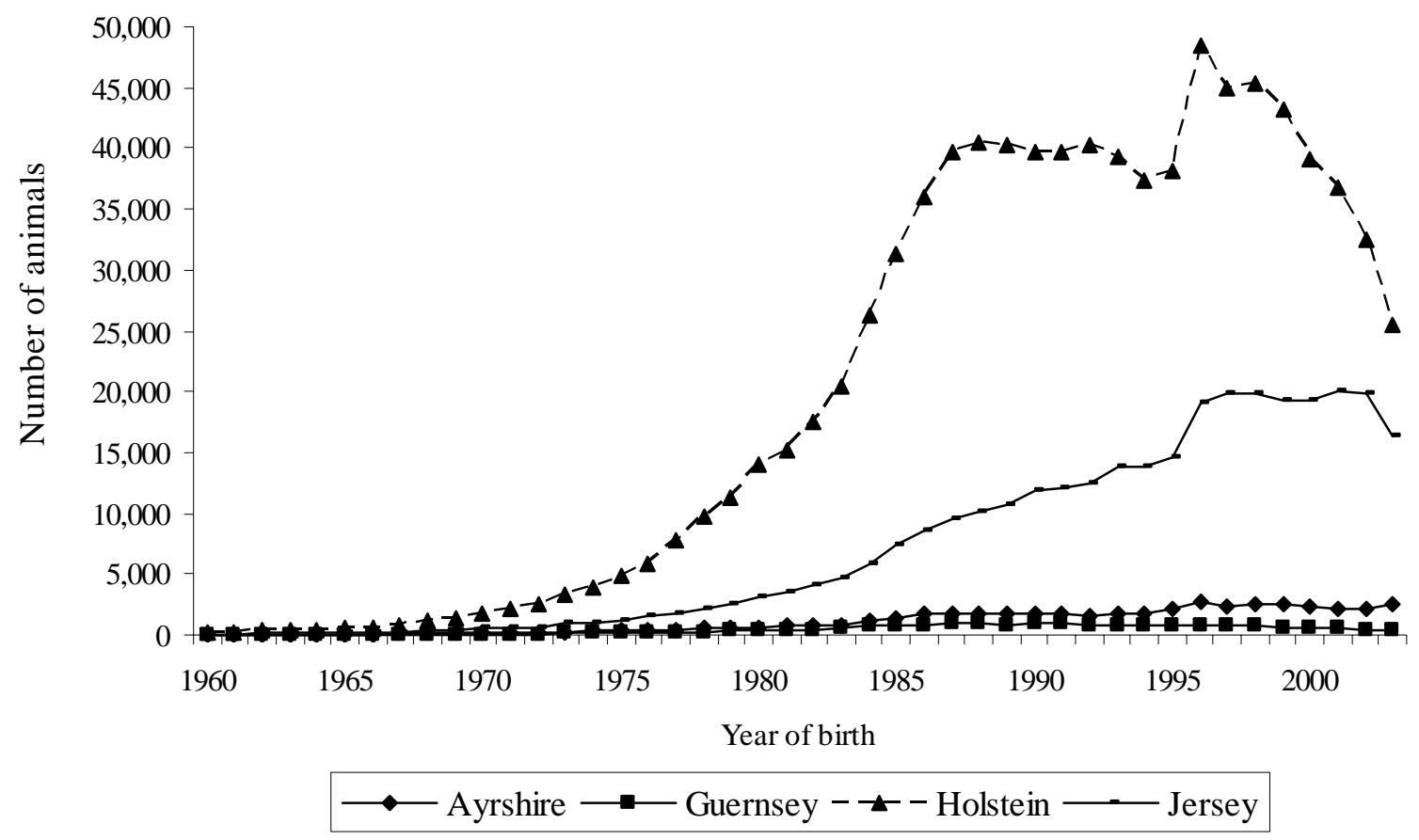

Figure 2 The annual registrations for the Ayrshire, Guernsey, Holstein and Jersey breeds

Table 1 Generation interval ${ }^{1}$ (in years) and rate of inbreeding ( $\Delta \mathrm{F}$ ) for the Ayrshire, Guernsey, Holstein and Jersey breeds

\begin{tabular}{|c|c|c|c|c|c|c|c|c|}
\hline \multirow{2}{*}{ Breed } & \multirow{2}{*}{$\mathrm{L}_{\mathrm{SS}}$} & \multirow{2}{*}{$\mathrm{L}_{\mathrm{DS}}$} & \multirow{2}{*}{$\mathrm{L}_{\mathrm{SD}}$} & \multirow{2}{*}{$\mathrm{L}_{\mathrm{DD}}$} & \multirow{2}{*}{ L } & \multicolumn{2}{|c|}{$\Delta \mathrm{F}$} & \multirow{2}{*}{$\mathrm{Ne}$} \\
\hline & & & & & & (\%/year) & (\%/generation) & \\
\hline Ayrshire & 8.83 & 6.39 & 7.53 & 5.04 & 6.95 & 0.05 & 0.34 & 148 \\
\hline Guernsey & 7.57 & 5.75 & 6.35 & 5.17 & 6.21 & 0.05 & 0.30 & 165 \\
\hline Holstein & 8.36 & 5.15 & 8.20 & 4.71 & 6.61 & 0.06 & 0.37 & 137 \\
\hline Jersey & 8.13 & 5.74 & 6.68 & 4.73 & 6.32 & 0.07 & 0.46 & 108 \\
\hline
\end{tabular}

\footnotetext{
${ }^{1}$ Generation interval for the pathway of the sire of sires $\left(\mathrm{L}_{\mathrm{SS}}\right)$; dam of sires $\left(\mathrm{L}_{\mathrm{DS}}\right)$; sire of dams $\left(\mathrm{L}_{\mathrm{SD}}\right)$;

and dam of dams $\left(\mathrm{L}_{\mathrm{DD}}\right)$ and average generation interval across pathways $(\mathrm{L})$; Ne - effective population size
}

The current levels of inbreeding within the four breeds are still lower than estimates of inbreeding obtained 15 years ago in the same breeds in the United States (Wiggans et al., 1995, Young \& Seykora, 1996). Thompson et al. (2000a; b) reported average inbreeding coefficients of $4.2 \%$ and $4.6 \%$ for the American Holstein and Jersey populations, respectively. Recently, a slightly lower inbreeding level (1.9\%) was reported for the Israeli Holstein (Weller \& Ezra, 2005). The mean inbreeding levels were reported to be 3.9\% and 3.4\% in 2003 in the Danish Holstein and Jersey breeds (Sørensen et al., 2005). Miglior \& Burnside (1995) also reported an increase in the levels of inbreeding in the Canadian Holstein population. However, these estimates may not be directly comparable to the results obtained in the current study because of different base years. For example, inbreeding coefficients in Thompson et al. (2000a; b) were computed based on pedigree traced until base animals were reached, i.e. there was no explicit base year. 
Considering the entire period (1960 to 2003) the most inbred animal was born in 1988 for the Ayrshire (37.5\%), 2003 for the Guernsey (30.5\%), 1985 for the Holstein (41.2\%), and 1991 for the Jersey (42.2\%). These high inbreeding coefficients suggest that even though the mean inbreeding in the four breeds is still low, occasional intense inbreeding does occur in these populations.

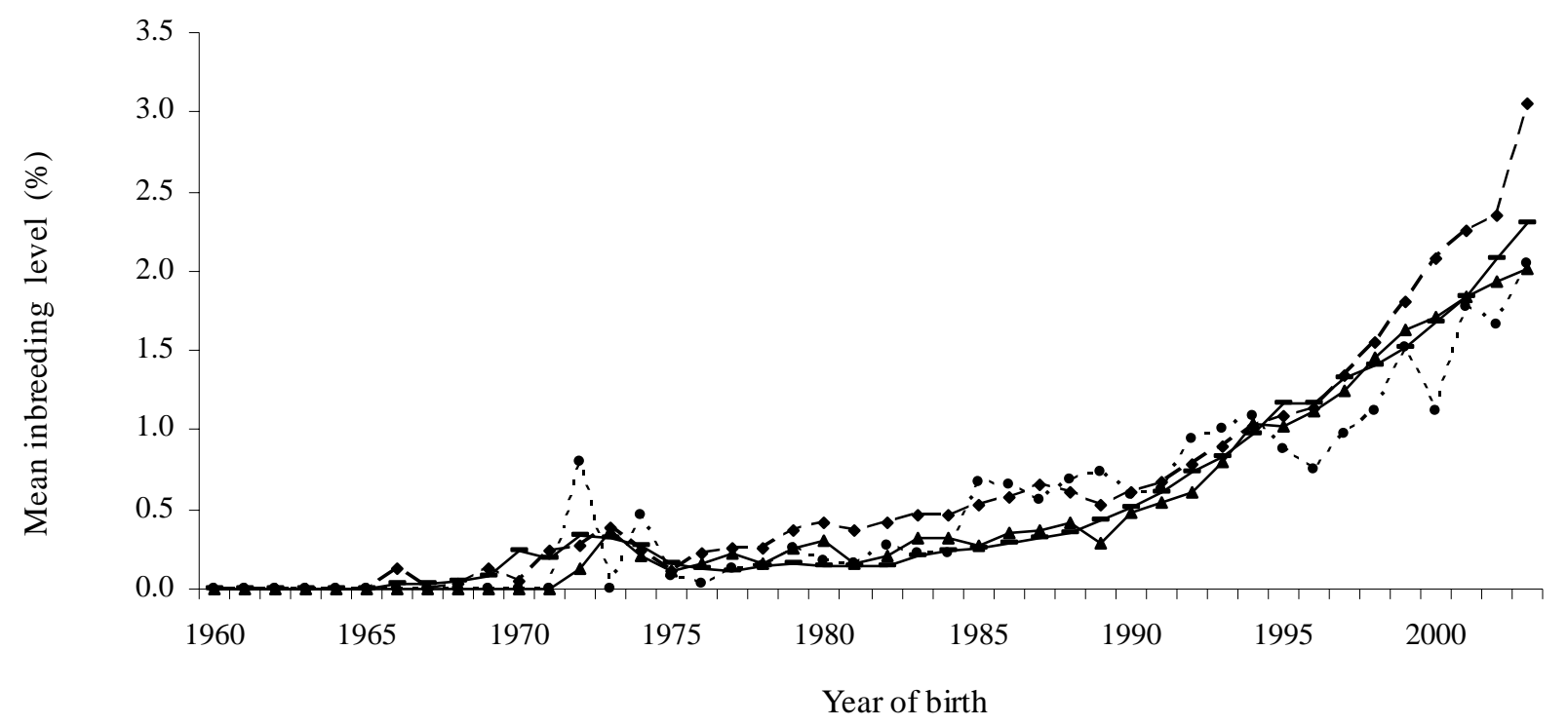

$\longrightarrow$ Ayrshire $\cdots \cdots \cdot$... Guernsey $\longrightarrow$ Holstein $-\rightarrow-$ Jersey

Figure 3 The annual mean inbreeding levels of the Ayrshire, Guernsey, Holstein and Jersey breeds

For illustrative purpose, the pedigree of the most inbred Jersey cow $(F=42.2 \%$; animal numbered 7) is given in Figure 4. Each path of this cow's pedigree was traced back until the foundation or base animals were reached. It can be noticed that this cow was a progeny of a mating between an inbred sire $(\mathrm{F}=12.5 \%$; animal numbered 4) and his inbred daughter ( $F=28.1 \%$; animal numbered 6). Figure 4 clearly demonstrates that animal 1 was overly represented in animal 7's pedigree. This result suggests that there seems to have been no intention to avoid mating between close relatives within this particular family.

The rates of inbreeding expressed per year and per generation are presented in Table 1 . The Jersey population exhibited the highest annual rate of inbreeding $(0.07 \%)$ followed by the Holstein $(0.06 \%)$ and the Ayrshire (0.05\%) and the Guernsey (0.05\%). The rate of inbreeding obtained in this study for the Holstein is similar to the rate of $0.05 \% / y r$ for the bulls and $0.079 \% / y r$ for the cows reported for the Israeli Holstein (Weller \& Ezra, 2005). Wiggans et al. (1995) reported the annual rates of inbreeding of $0.17 \%, 0.22 \%$, $0.20 \%$, and $0.21 \%$ for the United States Ayrshire, Guernsey, Holstein and Jersey. In a separate study of the United States Holstein population, Young \& Seykora (1996) used a random sample of the females born in 1990 and reported a rate of inbreeding that was about half that obtained by Wiggans et al. (1995). Wiggans et al. (1995) accounted for missing pedigree information when calculating the relationship by using the average relationships of the contemporaries for the unknown ancestors. Miglior \& Burnside (1995) found that inbreeding increased at different rates in the Canadian Holstein for period 1950 to 1990. The rates of inbreeding were calculated separately for the bulls and cows with the bulls showing the most dramatic increase of $0.21 \% / \mathrm{yr}$ compared to the $0.07 \% / \mathrm{yr}$ for the cows for the period 1987 to 1990 . Estimates of the rates of inbreeding obtained in the current study are still considerably lower than the critical level of $0.5 \% / \mathrm{yr}$ suggested for animal breeding programs (Nicholas, 1989). 


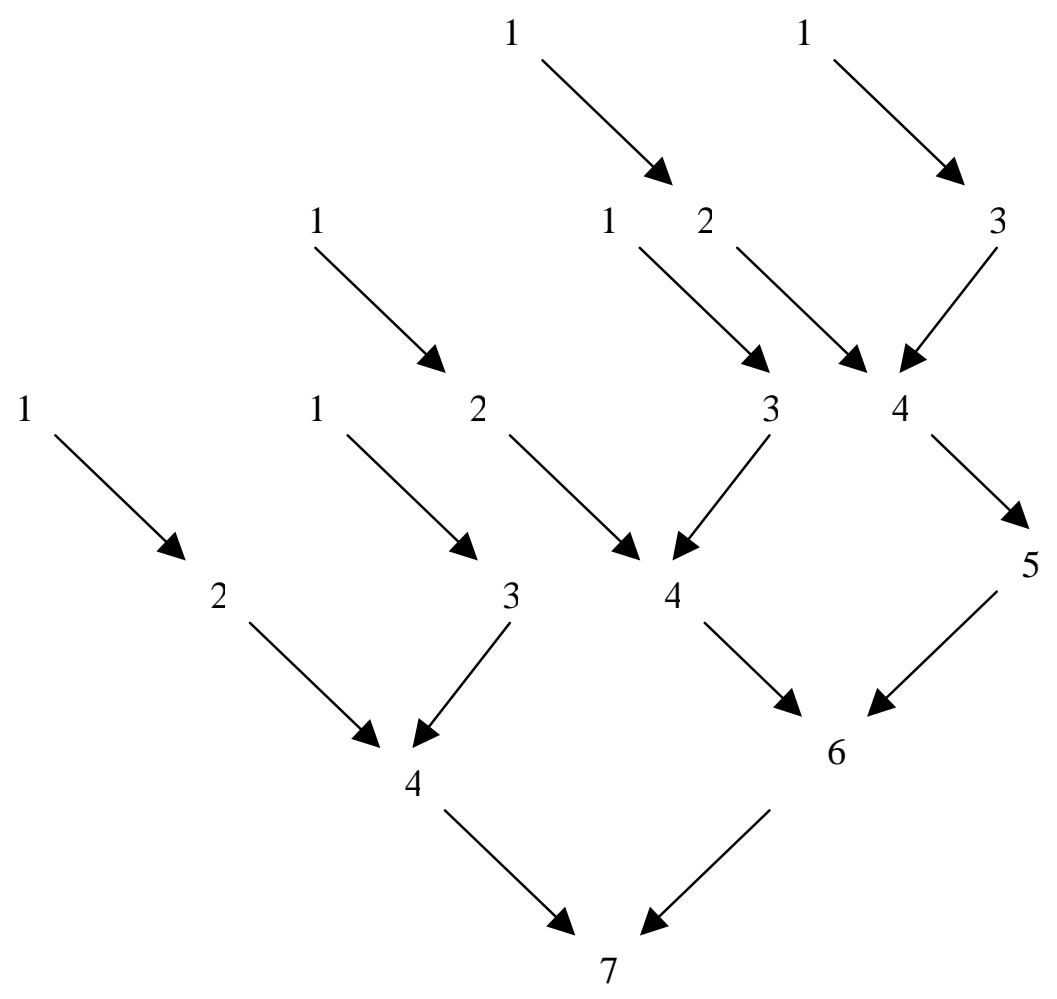

Figure 4 Diagram of the pedigree of the most inbred Jersey cow

Effective population size (Ne) is a measure of genetic variability within a population with large values of Ne indicating more variability and small values indicating less genetic variability. The estimates of effective population sizes were 148, 165, 137, and 108 for the Ayrshire, Guernsey, Holstein and Jersey, respectively (Table 1). The current estimate of effective population size for the Ayrshire was lower than that $(\mathrm{Ne}=161)$ of the American Ayrshire reported by Weigel (2001). Contrary to the estimates obtained in this study Weigel (2001) reported considerably lower estimates for the Guernsey (65), Holstein (39) and Jersey (30). Estimates of effective population sizes based on recent inbreeding trend (1993 to 2003) of 49 and 53 were reported for the Danish Holstein and Jersey populations respectively (Sørensen et al., 2005). It is interesting to note that numerically larger (Holstein and Jersey) breeds have lower effective population sizes in comparison to numerically smaller breeds (Ayrshire and Guernsey). One possible explanation for these results is the high selection intensities practiced by numerically larger breeds (Weigel, 2001).

Extensive use of certain sires results in an increase in the variance in family sizes (i.e. unequal genetic contribution to the next generation) which may reduce the effective population size (Falconer \& Mackay, 1996). For example 30, 20, 49 and 53\% of the progeny born in 2003 for the Ayrshire, Guernsey, Holstein and Jersey, respectively were sired by $5 \%$ of the prominent sires. The trend in the mean number of progeny per sire for the period 1960 to 2003 is presented in Figure 5. There was a general increase in the mean number of progeny per sire for all the breeds throughout the entire period. The current mean numbers of progeny per sire (2003) were 14.7, 5.8, 22.3, and 19.2 for the Ayrshire, Guernsey, Holstein and Jersey, respectively (Figure 5). This indicates that the half-sib family sizes tended to be smaller in Guernsey relative to the other three breeds. The mean progeny per sire was consistently higher in Holstein compared to the other breeds for the entire period. For the past 15 years, the mean number of progeny per sire in Holstein has stabilized at around 27 with a tendency for a decline in the recent years. A similar trend is evident in Guernsey while the Jersey and Ayrshire show a positive trend. 


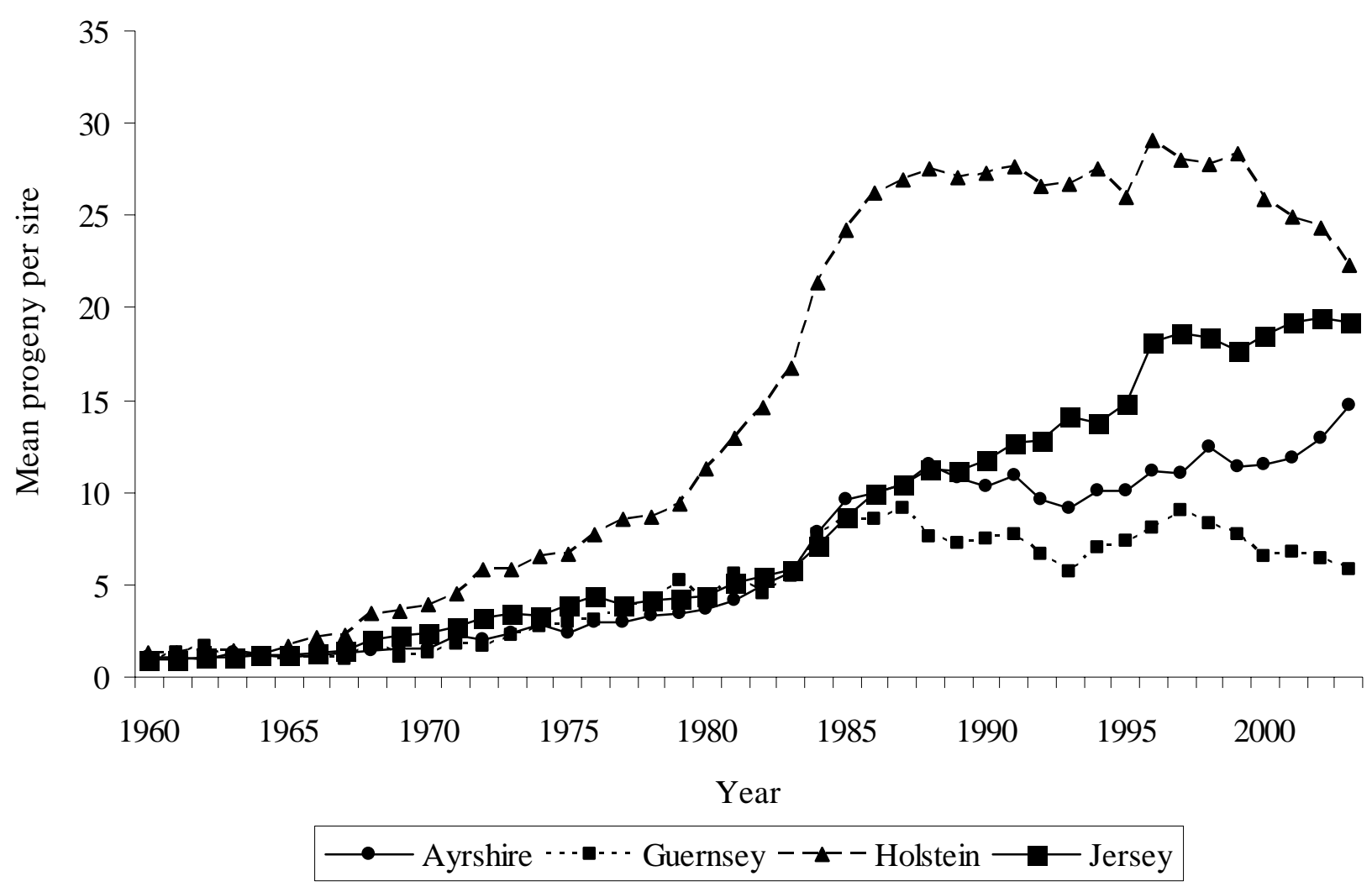

Figure 5 The mean progeny per sire for the Ayrshire, Guernsey, Holstein and Jersey breeds

\section{Conclusion}

The results of the current study provide evidence of differential rates of inbreeding in the four major South African dairy breeds. Even though the rate of inbreeding was comparable among the breeds, the accumulation of inbreeding is at a slightly higher rate in the Jersey population. One way to manage inbreeding will be through using mate allocation programs that put a limit or constraint on the level of inbreeding of the future progeny. Estimates of effective population sizes indicate that the genetic variability within the South African dairy breeds is still higher than that of their counterparts in the United States. While the rate of inbreeding and the effective population sizes have not yet reached critical levels, the existence of highly inbred individuals within these populations necessitates that a further study be conducted to quantify the phenotypic effect of inbreeding on traits of economic importance in these populations.

\section{Acknowledgements}

The authors wish to acknowledge D.J. Garrick and H.D. Blackburn for their valuable comments that greatly improved the manuscript. This research is a contribution of the Livestock Business Division (LBD) of the ARC and was partially supported by the Technology and Human Resources for Industry Programme (THRIP) grant.

\section{References}

Falconer, D.S. \& Mackay, T.F.C., 1996. Introduction to Quantitative genetics. Longman Group, Essex, UK. Golden, B.L., Snelling, W.M. \& Mallinckrodt, C.H., 1992. Animal breeder's tool kit user's guide and reference manual. Colorado State Univ. Agric. Exp. Sta. Tech. Bull. LTB 92-2.

Kearney, J.F., Wall, E., Villanueva, B. \& Coffey, M.P., 2004. Inbreeding trends and application of optimized selection in the UK Holstein population. J. Dairy Sci. 87, 3503-3509. 
Meuwissen, T.H.E. \& Luo, Z., 1992. Computing inbreeding coefficients in large populations. Genet. Sel. Evol. 24, 305-313.

Miglior, F. \& Burnside, E.B., 1995. Inbreeding of Canadian Holstein cattle. J. Dairy Sci. 78, 1163-1167.

Nicholas, F.W., 1989. In: Evolution and Animal Breeding. Eds. Hill, W.G. \& Mackay, T.F.C., CAB Intl., Wallingford, UK. pp. 201-209. (cited by Weigel, 2001).

Sørensen, A.C., Sørensen, M.K. \& Berg, P., 2005. Inbreeding in Danish dairy cattle populations. J. Dairy Sci. 88, 1865-1872.

Thompson, J.R., Everett, R.W. \& Hammerschmidt, N.L., 2000a. Effects of inbreeding on production and survival in Holsteins. J. Dairy Sci. 83, 1856-1864.

Thompson, J.R., Everett, R.W. \& Wolfe, C.W., 2000b. Effects of inbreeding on production and survival in Jerseys. J. Dairy Sci. 83, 2131-2138.

Weigel, K.A., 2001. Controlling inbreeding in modern breeding programs. J. Dairy Sci. 84 (E. Suppl.), E177-E184.

Wiggans, G.R., VanRaden, P.M. \& Zuurbier, J., 1995. Calculation and use of inbreeding coefficients for genetic evaluation of United States dairy cattle. J. Dairy Sci. 78, 1584-1590.

Weller, J.I. \& Ezra, E., 2005. Analysis of inbreeding in the Israeli Holstein dairy cattle population. Proc. 2005 Interbull meeting, Uppsala, Sweden, June 2-4, 85-87.

Young, C.W. \& Seykora, A.J., 1996. Estimates of inbreeding and relationships among registered Holstein females in the United States. J. Dairy Sci. 79, 502-505. 